\title{
PENGARUH KONSENTRASI KARAGENAN TERHADAP SIFAT FISIK, KIMIA DAN ORGANOLEPTIK MINUMAN JELI NANAS (Ananas comosus L. Merr )
}

\section{THE EFFECT OF CARRAGEENAN CONCENTRATION ON PHYSICAL, CHEMICAL AND ORGANOLEPTIC OF PINEAPPLE JELLY DRINKS}

(Ananas comosus L. Merr)

\author{
Lina Widawati ${ }^{1)}$, Hendri Hardiyanto ${ }^{2)}$ \\ 1) Program Studi Teknologi Pangan, Fakultas Pertanian, Universitas Dehasen Bengkulu \\ 2) Program Studi Teknologi Pertanian, Fakultas Pertanian, Universitas Dehasen Bengkulu \\ Email : lina84id@gmail.com
}

\begin{abstract}
ABSTRAK
Buah nanas disukai terutama karena sifat buah nanas yang berhubungan dengan aroma, rasa dan kenampakannya yang sangat menarik. Minuman jeli adalah minuman dengan viskositas tinggi yang dibuat dari sari buah khususnya buah yang mengandung pectin dengan penambahan gula, asam dan air. Penelitian ini bertujuan untuk mengetahui pengaruh konsentrasi karagenan terhadap sifat fisik, kimia dan organoleptik minuman jeli nanas (Ananas comosus L. Merr).

Metode dalam penelitian meliputi proses pembuatan minuan jeli yaitu penghancuran, penyaringan, pencampuran, pemanasan, pengangkatan, dan pengemasan. Perlakuan terhadap masing-masing sampel yaitu penambahan karagenan dengan konsentrasi $0,15 \%, 0,25 \%$, $0,35 \%, 0,45 \%, 0,55 \%$. Analisis pada penelitian ini meliputi kandungan vitamin $\mathrm{C}$, viskositas dan uji organoleptik (rasa, warna, dan tekstur).

Hasil analisa terhadap vitamin $\mathrm{C}$ minuman jeli nanas berkisar antara $1,13 \mathrm{mg} / \mathrm{g}$ hingga 1,92 $\mathrm{mg} / \mathrm{g}$. Analisa terhadap viskositas minuman jeli nanas berkisar antara 15,30 x 10 $0^{-3}$ hingga $18,05 \times 10^{-3}$. Nilai rerata terhadap warna berkisar antara 3,1 (agak suka) hingga 3,65 (agak suka), rerata rasa berkisar antara 3,2 (agak suka) hingga 3,6 (agak suka), dan rerata tekstur berkisar antara 3,25 (agak suka) hingga 3,85 (agak suka).
\end{abstract}

Kata Kunci: karagenan, minuman jeli, nanas

\section{ABSTRACT}

Pineapple preferred mainly related to flavor, taste and very interesting appearance. Jelly drink is a drink with high viscosity, with the addition of sugars, acids and water. This study aimed to determine the effect of carrageenan concentration on physical, chemical and organoleptic pineapple jelly drinks (Ananas comosus L. Merr).

The research methods include crushing, screening, mixing, heating, removaling, and packaging. Treatment of each sample are the addition of carrageenan concentration at 0.15 $\%, 0.25 \%, 0.35 \%, 0.45 \%, 0.55 \%$. The analysis in this study include vitamin C, viscosity and organoleptic (taste, color, and texture).

The result of analysis vitamin C pineapple jelly drinks ranged from $1.13 \mathrm{mg} / \mathrm{g}$ to $1.92 \mathrm{mg} / \mathrm{g}$. Analysis on the viscosity of the pineapple jelly drinks ranged between $15.30 \times 10^{-3}$ to $18.05 \times$ $10^{-3}$. The average value of the color range between 3.1 ( $a$ bit like) to 3.65 (a bit like), 
average of flavor ranges between 3.2 (a bit like) to 3.6 (a bit like), and the average of texture ranged between 3.25 (a bit like) to 3.85 (somewhat like).

Keywords : Carrageenan, jelly drinks, pineapple

\section{PENDAHULUAN}

Buah nanas disukai terutama karena sifat buah nanas yang berhubungan dengan aroma, rasa dan kenampakannya yang sangat menarik. Disamping itu juga karena nilai gizinya, dimana nanas mengandung vitamin $\mathrm{C}$ dan $\mathrm{A}$ (retinol) masing-masing sebesar $24 \mathrm{mg}$ dan $36 \mathrm{mg}$ tiap 100 gram. Vitamin A dan C tersebut berperan sebagai antioksidan yang mampu menghentikan pembentukan radikal bebas dalam tubuh. Buah nanas pada umumnya dikonsumsi dalam bentuk segar. Nanas bertekstur lunak sehingga dalam penyimpanan mudah mengalami kerusakan fisik, kimia dan mikrobiologi. Panen yang melimpah menyebabkan penurunan harga jual nanas. Oleh karena itu, diperlukan cara pengawetan melalui cara pengolahan lanjutan menjadi produk olahan yang memiliki nilai ekonomi yang tinggi seperti bentuk pasta, selai, dodol, sari buah, permen jeli, manisan kering serta produk dalam bentuk bubuk (Jelen, 1985).

Pengolahan nanas dalam bentuk lain salah satunya diolah menjadi minuman jelly drink. Minuman jeli adalah minuman dengan viskositas tinggi yang dibuat dari sari buah khususnya buah yang mengandung pektin dengan penambahan gula, asam dan air.Minuman jeli merupakan minuman ringan berbentuk gel, umumnya minuman jeli memiliki sifat elastis namun konsistensinya atau kekuatan gelnya lebih lemah bila dibandingkan jeli agar. Minuman jeli diharapkan menjadi alternatif minuman sari buah yang dapat mengatasi kestabilan sari buah karena minuman ini memiliki konsistensi gel sehingga dapat menghindari pengendapan, tetapi mudah diminum. Keunggulan dari minuman jeli yaitu bukan hanya sekedar minuman, tapi sekaligus dapat dipakai untuk menunda rasa lapar (Jelen, 1985).

Kriteria minuman jeli yang baik adalah mempunyai tekstur yang mantap, saat dikonsumsi menggunakan bantuan sedotan mudah hancur, namun bentuk gelnya masih terasa dimulut. Untuk membentuk struktur gel yang baik dan mudah di hisap harus ditambahkan gelling agent, jenis gelling agent yang cocok yaitu karagenan. Karagenan dapat membentuk struktur gel yang cenderung elastis dan kenyal. Sehingga, perlunya penelitian tentang pembuatan minuman sari buah berupa jelly drink dengan menggunakan karagenan. 


\section{METODE PENELITIAN}

\section{Bahan dan Alat}

Bahan-bahan yang digunakan pada penelitian ini adalah buah nanas, gula, karagenan, kalium sitrat, dan natrium benzoat.

Alat-alat yang digunakan untuk pembuatan minuman jeli yaitu pisau, blender, panci, kompor gas, kain saring, termometer, timbangan, baskom, cup .

\section{Metode}

Penelitian dilakukan denganmenggunakan Rancangan Acak Lengkap (RAL) dengan faktor perlakuan yaitu penambahan konsentrasi karagenan $0,15 \%$; $0,25 \%$; $0,35 \% ; 0,45 \%$ dan $0,55 \%$

Tahapan pengolahan minuman jeli nanas sebagai berikut:

1. Daging buah nanas ditimbang 300 gr.

2. Daging buah nanas dihancurkan dengan perbandingan daging buah dan air $1: 1$.

3. Daging buah yang telah hancur disaring dan diambil sari buah nanas sebanyak $500 \mathrm{ml}$.

4. Sari buah dicampurkan, gula $55 \%$, di panaskan dan diaduk hingga suhu $75^{\circ}$ C selama 3 menit.

5. Ditambahkan dengan karagenan dengan konsentrasi ( $0,15 \%, 0,25 \%$, $0,35 \%, 0,45 \%$ dan $0,55 \%$ ) dan natrium benzoate $0,1 \%$, dan asam sitrat $0,15 \%$, dipanaskan hingga suhu $90^{\circ} \mathrm{C}$ selama 5 menit.

6. Minuman jeli nanas dimasukkan ke dalam cup, dan didinginkan pada suhu ruang kemudian dianalisis.

Analisis penelitian yaitu dengan menganalisa kandungan vitamin $\mathrm{C}$ dan visikositas jelly drink nanas serta dilakukan uji organoleptik dengan parameter penilaian terhadap rasa, warna dan tekstur minuman jeli nanas dengan menggunakan panelis agak terlatih sebanyak 20 panelis.

\section{HASIL DAN PEMBAHASAN}

\section{Vitamin C Minuman Jeli Nanas}

Rerata hasil analisis vitamin $\mathrm{C}$ minuman jeli nanas dengan perlakuan penambahan karagenan sebanyak $0,15 \%, 0,25 \%$, $0,35 \%, 0,45 \%$, dan $0,55 \%$ dapat dilihat pada tabel 1 .

Tabel 1. menunjukan nilai rerata analisis kandungan vitamin $\mathrm{C}$ dengan perlakuan penambahan karagenan dengan konsentrasi $0,25 \%, 0,35 \%, 0,45 \%$ dan $0,55 \%$ tidak menunjukkan perbedaan yang nyata pada taraf 5\%. Penambahan konsentrasi $\quad 0,15 \%$ sebesar $1,92 \mathrm{mg} / \mathrm{g}$ berbeda nyata dengan perlakuan penambahan karagenan dengan konsentrasi $0,25 \%$ sebesar $1,38 \mathrm{mg} / \mathrm{g}$, konsentrasi $0,35 \%$ sebesar $1,18 \mathrm{mg} / \mathrm{g}$, konsentrasi karagenan $0,35 \%$ sebesar 1,23 
$\mathrm{mg} / \mathrm{g}$ dan konsentrasi karagenan 0,45\% sebesar $1,13 \mathrm{mg} / \mathrm{g}$. Vitamin $\mathrm{C}$ mudah larut dalam air dan mudah rusak dengan adanya panas, oksidasi dipercepat oleh cahaya (Winarno, 2008). Pada proses pembuatan minuman jeli, dilakukan proses-proses yang menyebabkan rusaknya vitamin $\mathrm{C}$ seperti, penghancuran dengan menggunakan blender yang menyebabkan terjadinya oksidasi serta perebusan pada suhu yang cukup tinggi.

Tingginya rata-rata nilai vitamin $\mathrm{C}$ pada perlakuan pemberian karagenan disebabkan oleh adanya penarikan partikel-partikel koloid yang lebih banyak pada sirup kulit nanas pada konsentrasi penstabil yang lebih tinggi. Kandungan vitamin C sirup kulit nanas dapat dipengaruh dari kandungan vitamin $\mathrm{C}$ yang terdapat pada buah nanas sebagai bahan baku penggolahan sirup kulit nanas. Haryanto dan Beni (2006), melaporkan bahwa kadar vitamin $\mathrm{C}$ pada buah nanas matang sebesar 22,4 mg per $100 \mathrm{~g}$.

\section{Viskositas Minuman Jeli Nanas}

Viskositas adalah derajat kekentalan suatu produk pangan (Buckle et al, 2000). Rerata hasil analisa viskositas minuman jeli nanas dengan perlakuan penambahan karagenan sebanyak 0,15\%, 0,25\%, $0,35 \%, 0,45 \%$, dan $0,55 \%$ dapat dilihat pada tabel 2 .

Tabel 2 menunjukan nilai rerata analisa viskositas dengan perlakuan penambahan karagenan dengan konsentrasi 0,15\%, $0,25 \%, \quad 0,35 \%, \quad 0,45 \%$ dan $0,55 \%$ menunjukkan perbedaan yang nyata pada taraf $5 \%$.

Tabel 1. Hasil Analisis Vitamin C Minuman Jeli Nanas

\begin{tabular}{cc}
\hline Konsentrasi Karagenan (\%) & Kandungan Vitamin C (mg/g) \\
\hline 0,15 & $1.92 \mathrm{a}$ \\
0,25 & $1.38 \mathrm{~b}$ \\
0,35 & $1.18 \mathrm{~b}$ \\
0,45 & $1.23 \mathrm{~b}$ \\
0,55 & $1.13 \mathrm{~b}$
\end{tabular}

Ket :Angka yang diikuti oleh kode huruf yang berbeda menunjukkanadanya perbedaan yang nyata pada taraf signifikansi $5 \%$. 
Tabel 2. Hasil Analisis Viskositas Minuman Jeli Nanas

\begin{tabular}{cc}
\hline Konsentrasi Karagenan $(\%)$ & Viskositas (Poise) \\
\hline 0,15 & $15.78 \times 10^{-3} \mathrm{~d}$ \\
0,25 & $15.30 \times 10^{-3} \mathrm{e}$ \\
0,35 & $16.27 \times 10^{-3} \mathrm{c}$ \\
0,45 & $16.94 \times 10^{-3} \mathrm{~b}$ \\
0,55 & $18.05 \times 10^{-3} \mathrm{a}$
\end{tabular}

Ket :Angka yang diikuti oleh kode huruf yang berbeda menunjukkanadanya perbedaan yang nyata pada taraf signifikansi $5 \%$.

Nilai rerata viskositas minuman jeli nanas dengan semakin besar konsentrasi penambahan karagenan maka viskositas semakin tinggi, viskositas minuman jeli nanas dengan penambahan konsentrasi $0,15 \%$ sebesar $15.78 \times 10^{-3}$, penambahan karagenan dengan konsentrasi 0,25\% sebesar $15.30 \times 10^{-3}$, konsentrasi $0,35 \%$ sebesar 16.27 x $10^{-3}$, konsentrasi karagenan $0,45 \%$ sebesar $16.94 \times 10^{-3}$ dan konsentrasi karagenan $0,55 \%$ sebesar $18.05 \times 10^{-3}$. Viskositas minuman jeli nanas yang paling tertinggi pada perlakuan penambahan karagenan dengan konsentrasi $0,55 \%$.

Semakin tinggi konsentrasi karagenan yang ditambahkan maka viskositas semakin tinggi, hal ini dapat disebabkan oleh air bebas yang terdapat pada sari nanas diikat oleh molekul-molekul dari gugus hidrofilik karagenan sehingga berbentuk gel. Semakin tinggi konsentrasi karagenan maka banyak jumlah air bebas yang diserap dan diikat sehingga keadaan jeli menjadi lebih kuat (Sugiarso, 2015). Sedangkan menurut Buckle et al (2000), penambahan karagenan juga berpengaruh pada tingkat viskositas, karena fungsi karaginan yaitu sebagai bahan pengental. Penambahan karagenan dapat meningkatkan viskositas hidrokoloid, karena karaginan mempunyai sifat hidrokoloid. Viskositas suatu hidrokoloid dipengaruhi oleh beberapa faktor yaitu konsentrasi karagenan, temperatur dan jenis karagenan.

\section{Sifat Organoleptik Warna Minuman}

\section{Jeli Nanas}

Rerata hasil warna minuman jeli nanas dengan perlakuan penambahan karagenan sebanyak $0,15 \%, 0,25 \%, 0,35 \%, 0,45 \%$, dan $0,55 \%$ dapat dilihat pada tabel 3 . 
Tabel 3. Hasil Analisis Warna Minuman Jeli Nanas

\begin{tabular}{cc}
\hline Konsentrasi Karagenan $(\%)$ & Warna \\
\hline 0,15 & $3.4 \mathrm{a}$ \\
0,25 & $3.2 \mathrm{ab}$ \\
0,35 & $3.1 \mathrm{~b}$ \\
0,45 & $3.65 \mathrm{a}$ \\
0,55 & $3.25 \mathrm{ab}$
\end{tabular}

Ket : Angka yang diikuti oleh kode huruf yang berbeda menunjukkan adanya perbedaan yang nyata pada taraf signifikansi $5 \%$. Skala : $1=$ sangattidak suka; $2=$ tidak suka; 3 = agak suka; $4=$ suka; $5=$ sangat suka

Tabel 3. menjelaskan nilai rerata uji sensoris terhadap warna minuman jeli nanas yang menunjukkan tidak bedanyata pada taraf signifikan $5 \%$. Nilai rerata warna minuman jeli nanas dengan perlakuan konsentrasi karagenan $0,15 \%$ sebesar 3,4 (agak suka), karagenan 0,25\% dengan penilaian 3,2 (agak suka), karagenan $0,35 \%$ dengan penilaian 3,1 (agak suka), karagenan $0,45 \%$ dengan penilaian 3,65 (suka) dan penambahan karagenan konsentrasi $0,55 \%$ dengan penilaian 3,25 (agak suka). Penambahan karagenan dengan konsentrasi $0,45 \%$ menunjukkan penilaian tertinggi yaitu sebesar 3,65, dimana penambahan karagenan yang semakin tinggi tidak mempengaruhi warna dari minuman jeli nanas. Warna minuman jeli nanas yang ditimbulkan dapat dipengaruhi oleh warna dari sari nanas yang diperoleh serta penambahan gula pada proses pengolahan minuman jeli nanas. Penambahan karaginan pada pembuatan jelly drink berfungsi sebagai gelling agent (bahan pembentuk gel). Menurut Putra (2013) bahwa warna karagenan yang putih kekuning-kuningan tidak berpengaruh terhadap produk yang dihasilkan karena produk didominasi oleh warna dari bahan baku yang digunakan. Seperti dinyatakan oleh Estiasih (2006) bahwa fungsi utama agar adalah sebagai pemantap, penstabil, pengemulsi, pengental, pengisi, penjernih, pembuat gel, dan lain-lain.

\section{Sifat Organoleptik Rasa Minuman Jeli}

\section{Nanas}

Rerata hasil rasa minuman jeli nanas dengan perlakuan penambahan karagenan sebanyak $0,15 \%, 0,25 \%, 0,35 \%, 0,45 \%$, dan $0,55 \%$ dapat dilihat pada tabel 4 . 
Tabel 4. Hasil Analisis Rasa Minuman Jeli Nanas

\begin{tabular}{cc}
\hline Konsentrasi Karagenan(\%) & Rasa \\
\hline 0,15 & $3.45 \mathrm{a}$ \\
0,25 & $3.35 \mathrm{ab}$ \\
0,35 & $3.2 \mathrm{ab}$ \\
0,45 & $3.6 \mathrm{a}$ \\
0,55 & $3.05 \mathrm{~b}$
\end{tabular}

Ket : Angka yang diikuti oleh kode huruf yang berbeda menunjukkan adanya perbedaan yang nyata pada taraf signifikansi $5 \%$.Skala : $1=$ sangattidak suka; $2=$ tidak suka; 3 = agak suka; $4=$ suka; 5 = sangat suka

Tabel 4. menjelaskan nilai rerata uji sensoris terhadap rasa minuman jeli nanas yang menunjukkan tidak bedanyata pada taraf signifikan $5 \%$. Nilai rerata warna minuman jeli nanas dengan perlakuan konsentrasi karagenan $0,15 \%$ sebesar 3,45 (agak suka), karagenan 0,25\% dengan penilaian 3,35 (agak suka), karagenan $0,35 \%$ dengan penilaian 3,2 (agak suka), karagenan $0,45 \%$ dengan penilaian 3,6(suka) dan penambahan karagenan konsentrasi $0,55 \%$ dengan penilaian 3,05 (agak suka). Selisih skor penilaian panelis terhadap rasa minuman jeli tidak terlalu besar. Penambahan karagenan dengan konsentrasi yang berbeda tidak mempengaruhi rasa minuman jeli nanas, hal ini disebabkan komposisi bahan dalam pengolahan minuman jeli nanas sama antara gula, asam sitrat dan sari nanas yang digunakan setiap perlakuan sehingga panelis memberikan penilaian dengan skala agak suka. Menurut Rachman
(2005), bahwa karagenan memiliki karakteristik yaitu tepung bubuk putih sampai coklat terang dan tidak menimbulkan rasa.

\section{Sifat Organoleptik Tekstur Minuman}

\section{Jeli Nanas}

Rerata hasil tekstur minuman jeli nanas dengan perlakuan penambahan karagenan sebanyak $0,15 \%, 0,25 \%, 0,35 \%, 0,45 \%$, dan $0,55 \%$ dapat dilihat pada tabel 5 . Nilai rerata uji sensoris terhadap tekstur minuman jeli nanas yang menunjukkan tidak bedanyata pada taraf signifikan $5 \%$. Nilai rerata warna minuman jeli nanas dengan perlakuan konsentrasi karagenan $0,15 \%$ sebesar 3,25 (agak suka), karagenan $0,25 \%$ dengan penilaian 3,65 (suka), karagenan $0,35 \%$ dengan penilaian 3,35 (agak suka), karagenan 0,45\% dengan penilaian 3,85 (suka) dan penambahan karagenan konsentrasi 0,55\% dengan penilaian 3,4 (agak suka). 
Tabel 5. Hasil Analisis Tekstur Minuman Jeli Nanas

\begin{tabular}{cc}
\hline Konsentrasi Karagenan (\%) & Tekstur \\
\hline 0,15 & $3.25 \mathrm{~b}$ \\
0,25 & $3.65 \mathrm{ab}$ \\
0,35 & $3.35 \mathrm{ab}$ \\
0,45 & $3.85 \mathrm{a}$ \\
0,55 & $3.4 \mathrm{ab}$
\end{tabular}

Ket : Angka yang diikuti oleh kode huruf yang berbeda menunjukkan adanya perbedaan yang nyata pada taraf signifikansi 5.Skala : $1=$ sangattidak suka; $2=$ tidak suka; $3=$ agak suka; $4=$ suka; $5=$ sangat suka

Penilaian terhadap tekstur tertinggi pada perlakuan konsentrasi karagenan sebanyak $0,45 \%$, dimana tekstur dari minuman jeli nanas sudah sesuai dengan kriteria minuman jeli. Kriteria jelly drink yang baik adalah mempunyai tekstur yang mantap saat dikonsumsi menggunakan sedotan mudah hancur, namun bentuk gelnya terasa di mulut, mempunyai warna, rasa, aroma dan kenampakan yang sebanding dengan produk segar dan masih memiliki nilai gizi yang tinggi.

Karagenan merupakan bahan yang digunakan sebagai bahan pembentuk gel pada pembuatan produk makanan. Karagenan merupakan senyawa hidrokoloid yang dapat berfungsi sebagai pengental (Winarno, 2002), sehingga penambahan karagenan dapat mempengaruhi tekstur minuman jeli. Penambahan karagenan juga berpengaruh pada tingkat viskositas, karena fungsi karagenan yaitu sebagai bahan pengental.
Penambahan karagenan dapat meningkatkan viskositas hidrokoloid, karena karaginan mempunyai sifat hidrokoloid. Viskositas suatu hidrokoloid dipengaruhi oleh beberapa faktor yaitu konsentrasi karagenan, temperatur dan jenis karagenan (Noer, 2006).

\section{Simpulan}

1. Hasil analisis terhadap vitamin C minuman jelinanas berkisar antara $1,13 \mathrm{mg} / \mathrm{g}$ hingga $1,92 \mathrm{mg} / \mathrm{g}$. Penambahan karagenan dengan konsentrasi semakin tinggi kandungan vitamin $\mathrm{C}$ dalam minuman jeli nanas semakin menurun.

2. Hasil analisis terhadap viskositas minuman jeli nanas berkisar antara $15,30 \times 10^{-3}$ hingga $18,05 \times 10^{-3}$. Penambahan karagenan dengan konsentrasi yang semakin tinggi mempengaruhi viskositas minuman jeli nanas yang semakin tinggi. 
3. Hasil analisis organoleptik terhadap warna, rasa dan tekstur minuman jeli nanas menunjukkan tidak beda nyata. Nilai rerata terhadap warna berkisar antara 3,1 (agak suka) hingga 3,65 (agak suka), rerata rasa berkisar antara 3,2 (agak suka) hingga 3,6 (agak suka), dan rerata tekstur berkisar antara 3,25 (agak suka) hingga 3,85 (agak suka).

\section{DAFTAR PUSTAKA}

Buckle, K. A., R. A. Edwards, G. H. Fleet, dan M. Wooton. 2000. Ilmu Pangan. Terjemahan oleh $\mathrm{H}$. Purnomo dan Adiono. UI Press. Jakarta

Estiasih, T., 2006. Teknologi dan Aplikasi Polisakarida dalam Pengolahan Pangan. Penerbit Fakultas Teknologi Pertanian. Universitas Brawijaya. Malang.

Haryanto, E dan Beni. H. 1996. Nanas. Penebar Swadaya. Jakarta

Jelen, Pavel. 1985. Introduction to Food Processing. Reston Publishing Company. Virginia
Noer H. 2006. Hidrokoloid dalam Pembuatan Jelly Drink. Food Review. Vol 1 Edisi 2 Maret 2006.

Putra, B.P. 2013. Pengaruh Jenis dan Proporsi Bahan Pembentuk Gel terhadap Hasil Jadi Minuman Jeli Kunyit Asam. Skripsi. Program Pendidikan Tata Boga. Fakultas Teknik Universitas Negri Surabaya. Surabaya

Rachman, A. 2005. Pengaruh Penambahan Karagenan dan Agar-Agar pada Berbagai Konsentrasi Terhadap Sifat Fisik, Kimia, dan Organoleptik "Jelly Drink" Tomat (Lycopercium estelumtum Mill). Skripsi. Jurusan Teknologi Hasil Pertanian. Fakultas Teknologi Pertanian. Universitas Brawijaya. Malang

Sugiarso A, Nisa FC. 2015. Pembuatan Minuman Jeli Murbei (Morus alba l.)dengan Pemanfaatan Tepung Porang (A.Muelleri blume) sebagai Pensubtitusi Karagenan. Jurnal Pangan dan Agroindustri Vol. 3 No 2

Winarno FG. 2002. Kimia Pangan dan Gizi. Gramedia Pustaka Utama,Jakarta.

Winarno. 2008. Kimia Pangan dan Gizi. M-Brio Press. Bogor 